\title{
A GIS-Based Road-Mapping Network for Responding to Future Terrorist Activities in Colombo, Sri Lanka
}

\author{
Rev. Pinnawala Sangasumana, PhD \\ University of Sri Jayewardenepura, Sri Lanka \\ Marabage Upul Krishantha, BSc \\ Police Department, Sri Lanka \\ Ratnayake, R.M.K., PhD \\ University of Sri Jayewardenepura, Sri Lanka
}

Doi:10.19044/esj.2020.v16n8p159 ～URL:http://dx.doi.org/10.19044/esj.2020.v16n8p159

\begin{abstract}
The contemporary world has been moving to a new direction where anti-terrorist strategies are adopted intelligently to confront new challenges of global terrorism. Sri Lanka experienced a brutal terrorist attack again just recently after a decade of the total defeat of one of the dangerous terrorist organizations in the World, Liberation Tigers of Tamil Eelam (LTTE), in 2019. The LTTE demanded the Northern and Eastern provinces. Colombo had been a major vulnerable location and the LTTE had been frequently carrying out attacks against civilian targets, key politicians, government officials, military installations, as well as economic and commercial targets for about three decades. This paper therefore focuses on the applicability of GIS-based road-mapping analysis to respond to future terrorist activities based on the previous experience of terrorist attacks in Sri Lanka. Based on the methodology used in this study, 29 GN Divisions of Colombo DSD were selected as research sites and network, and hotspots analysis were then employed. Research results revealed that there were approximately 97 vulnerable locations at marginalized spaces. Distance from security installation to vulnerable location ranges from $0.8 \mathrm{~km}$ to $2.4 \mathrm{~km}$. Average responding time to any adversary action varies from 3 to 5 minutes. Junctions within the $400 \mathrm{~m}$ to $500 \mathrm{~m}$ distance from all vulnerable locations in the study area were identified as suitable road blocking points. Six GNDs were identified as major potential areas for terrorist activities. Petta and its neighboring wards seem to be the most vulnerable locations for terrorist activities in the future. Based on the accurate information from particular areas, terrorist activities can be monitored and prevented by this risk and emergency management road network system.
\end{abstract}


Keywords: Risk management, GIS, road network, security alert, terrorist attacks

\section{Introduction}

In today's world, terrorism has emerged as one of the extraordinary global challenges to the sovereign power of nation-states. Researchers have attempted to study this problem from different perspectives including movement of terrorist activities and their development, the complex relationship between terrorist attacks and physical and human landscape settings, as well as the response of security forces and the intelligent groups to various types of terrorist activities.

There is yet to be an official definition of terrorism. Some sources focus on terrorist tactics to define the term, while others focus on the actor (Yonah, 1976). Simon (1994) reports that at least 212 different definitions of terrorism exist across the world and 90 of them are recurrently used by governments and other institutions. Generally, the definition of terrorism entails the broad description of unlawful threatening employed to frighten a population to bring law and order with the intention of intimidating or coercing societies or governments based on personal, ideological or political reasons. The Oxford English Dictionary defines the term 'terrorism' as the unofficial or unauthorized use of violence and intimidation in the pursuit of political aims. This means that any offence committed by individuals or groups who resort to violence or threatening against a country, its institutions, its population in general or individuals in specific is intended to create a climate of terrors among official authorities, certain individuals or groups in society, or the general public.

Considering the various aspects on terrorism, it is evident that terrorist activities cannot be predicted, measured, as well as prejudged. However, on the level of national and international security system, all necessary measures which are being taken in the world today are terrorized and ravaged by separatism and extremism which is conquered by militant and ideological groups.

Sri Lanka has experienced some of the worst known acts of modern terrorism such as suicide bombings, massacre of civilians, and assassination of political and social leaders. Over time, these events have posed significant threats to the society, its economy, and its development. It also has a longlived experience in confronting and preventing terrorist threats and attacks for over 40 years. Therefore, the experiments of security strategies in targeting future terrorist attacks would contribute new knowledge to the world. Contrary to popular perception, Tamil insurgency originated in northern Sri Lanka in the early 1970s and gradually devolved into terrorism and the wider threat 
posed to domestic security. The LTTE had frequently carried out attacks against civilian targets, key politicians, government officials, military installations, and economic and commercial targets within Colombo and its suburb. Having faced fearful experiences during the war (LTTE attacks), Modara, Kotahena, Fort, Maradana, Maligawatta, and Pettah were identified as the most vulnerable locations in Colombo and suburbs. The end of the brutal war that lasted almost three decades may serve as an opportunity to develop and implement a GIS-based road-mapping network analysis system for responding to future terrorist activities and acquiring accurate information with key statistical data regarding particular areas. This would help limit terrorist activities, prevent and minimize human losses, and ensure that emergency management is done before and after terrorist strikes.

\section{Research Problem}

Today, Sri Lanka is one of the unsecure countries in the Asian region and the vulnerability of the national security is again under threat following the incident of Easter Sunday 2019. The church bombings were carried out during Easter services in Negombo, Batticaloa, and Colombo. The hotels that were bombed were the Shangri-La, Cinnamon Grand, Kingsbury, and Tropical Inn. All suicide bomb attacks were done by Sri Lankan citizens associated with National Thowheeth Jama'ath, a local militant Islamist group with suspected foreign ties, previously known for attacks against Buddhists and Sufis. During this research on the security installations in Colombo, a number of fields were identified as vulnerable locations within the city, including key economical places. As a result, catastrophic cyber threats were exposed. Also, abandoned weapons and explosives were uncovered in areas of the country formerly controlled by the terrorists. Besides, the level of threat against VVIPs could possibly be under-analyzed which poses further concerns on the capabilities of the terrorist attacks.

Against this background, Sri Lanka has to implement a new military factor in the global and internal security spectrum, which should reckon future operational planning to safeguard the nation's infrastructure. This fact has become a top priority item in order to effectively coordinate their security strategies to the mutual advantage of respective authorities as well as to evolve greater strategic convergence on counterterrorism activities. Hence, the study focuses on analyzing and implementing the road-mapping system and its process, as well as the GIS application in the military and intelligence field that can be exploited by respective authorities. The final result would encourage the decision-making process to assist with resolving security lapses which directly threaten National Security.

Developing a GIS-Based road-mapping network for responding to terrorist activities is the most vital area for Colombo and suburbs which 
directly affects national security. GIS has been a proficient tool in upgrading the efficiency of threat assessment, calculating the distance between any vulnerable points, performing shortest route analysis for service areas (security instillations), querying for finding roads under threat analysis, finding details of vulnerable points and areas (safe houses), etc.

As a structure that forecasts a future event, the target area has to be identified in terms of threats evaluation, vulnerabilities, future capability, and terrorists' intention. The system management of the intelligence effort should be implemented to take a preventive action and dismantle the terrorist wake up cells from the identification of the need for data to the final delivery of an intelligence product for the defense authorities. Thus, this will enable effective network analysis by using GIS Application for strengthening and enhancing security monitoring systems. Furthermore, the study may enable the monitoring of the pattern of terrorist's ideology of detrimental purpose through past experience to also restrain their activities.

\section{Literature Review}

The geographical aspect of terrorism is particularly constrained by the spatial pattern and process of sudden attacks and targets. Bahgat and Medina (2014) have emphasized the significance of a geographic perspective to conflict studies with three particular contributions. The temporal pattern of terrorism is very difficult to demarcate, no clear trend is visible, and the series is greatly influenced by spectacular events. This includes the method of measurement having specific weaknesses, the date of a planned incident not known, or the incident actually taking place, as well as lack of information regarding recruitment, and sufficient temporal data existing to identify basic patterns of preparatory conduct. The spatial pattern of terrorist activities and that of international and local terrorists who are remarkably similar also vary in interest on terrorist activities. Most of the time, terrorism can be shown as differences between territorial or non-territorial terrorism, developed or nondeveloped category, and expansions of Muslim extremism at global terrorism and possibility of multiple terrorist groups. These groups, however, are operating with different territorial capacities and goals with the resulting attack pattern. However, it has been revealed that the contribution of geographers as well as their interest in terrorism research literature is policyoriented rather than empirical or critical (Bahgat \& Medina, 2014). Geographic perspective has been widely used in terrorism literature with the attacks against America on September 11th, 2001, which motivated new research funding that would eventually attract greater attention and efforts from geographers. Recent literature on Geographic terrorism shows that most of the applied geographers who were motivated by the perceived benefits of 
the GIS are much more concerned with quantifying their findings on this field (Richardson, 2002).

GIS, as a tool for identifying and analyzing spatiality of a particular phenomenon, has a significant importance in developing a road-mapping network to respond to terrorist activities. This initiative has proved to be of considerable advantage for the effective performance of the security and the intelligence organizations. Similarly, it was observed that the technical limitations and poor knowledge about the analytical software would be a significant error for Emergency Rapid Troops (ERT). GIS could be a strong tool to be traced and monitored and also to be used for making analytical decisions by using models involving several map overlays. Since the potential of using GIS efficiently will be a very important factor for the assessment of public security in the abovementioned areas as well, this study would be an effective contribution to national security.

Re-examining the Al Qa'ida threat to the United States, Jones (2017) investigated the April 2013 Boston Marathon bombing and its development against the US homeland and also the latest attack of the Tsarnaev brothers in Boston, USA. Due to proper road network system, the second suspect of the attack was arrested within a short time. All terrorist organizations in the world may have used similar tactics over safe house concept such that they were able to use several safe houses in the study area. Therefore, several locations in the study area have to be seen as being maintained by some sympathizers as safe houses. Modara and Kotahaena in Colombo North can be identified as the most vulnerable and significant locations compared to other areas. Fair (2004) has explained the lapses in Colombo security based on false details without enough ground knowledge. A premier intelligence organization in Sri Lanka, the State Intelligence Service (SIS), Directorate of Military Intelligence (DMI), Directorate of Navy Intelligence (DNI) and all other sister organizations of Police and Military were carrying out real-time intelligence operations to destroy and identify the terrorists' intelligence and military (suicide) cells in Colombo and suburb. Chandraprema (2013) clearly confirms the intelligence organization's sharing and contributions. In the suicide attack on Mr. Gotabaya Rajapaksa, Secretary of Ministry of Defense and Urban Development, there was credible evidence of how the LTTE had plans to use its war strategy by infiltrating into low-income Tamil people in the Modara area as well as establishing the safe house in this area to complete their suicide mission. This would serve as a good place to explore their lifestyle. Thus, the focus of this study is to implement and develop a GIS-Based road-mapping network analysis system.

During the long-running war against the Eelam terrorism in Sri Lanka, the security forces and Police had been using traditional planning methods by using grid maps, reports, tables, historical records, and ground experience of 
the troops for pursuit of terrorists in Colombo. Also, the availability of data capturing showed very limited knowledge on Geographic Information System (GIS) as an analytical tool. Creation of Response Performance Zones in developing standards for coverage is necessary to examine areas and perform statistical analysis of response performance within those areas. Using GIS, calls can be geocoded to their specific locations. This will create a very busy pin map which is supported by all of the data with each call. Sets of calls can then be captured using the GIS and exported to a statistical analysis program for evaluation. Response zones can be created based on workload, fire demand, and response times rather than traditional response time criteria (Alexander, 2012).

\section{Methodology}

The GIS-based road network analysis system design deals with historic incidents data, ongoing data gathering (based on intelligence aspect), collection of geometric and attribute data, and creating a secure and safe road network system. Colombo is the capital city in Sri Lanka and it has been confronting a series of terrorist attacks for the last three decades. The research site consists of 29 Grama Niladari Divisions (GND) in Colombo North Divisional Secretariat Division (DSD) which is demarcated northward to Kelani River, southward to Galle Face Green, eastward to Baseline Road, and westward to Colombo Harbour. A spatial extent of approximately $40.188 \mathrm{~km}^{2}$ which is referred to as the study area is in the western province in Sri Lanka. Geographically, it lies between the $6^{\circ} 58.694 ' \mathrm{~N}$ and $6^{\circ} 55.794 ' \mathrm{~N}$ Latitude, and $79^{\circ} 52.100 \mathrm{E}$ and $79^{\circ} 52.708^{\prime} \mathrm{E}$ Longitude (Figure 1). This research site mainly focuses on safe houses, roadblocks, population density, terrorist sympathizer's locations, storage facilities for arms and explosives, communication centers, and relevant information.

Most of the terrorist activities carried out by the LTTE were recorded in the study area during the last three decades. They were mass distractions, sabotages, and violence which led to instantly widespread fear and attacks on innocent people such as suicide attacks, explosive bombing by using improvised explosive devices (IEDs) and ground attacks. Additionally, it is assumed that there are many possibilities of several suicide bomb attacks of Islamic terrorism to be directed to the key places in this area in the future. This is the main reason why Modara, Kotahena, Maradana, and Pettah areas have been identified and selected as the study area. 
Table 1: Population Density of the Study Area

\begin{tabular}{|c|c|c|c|c|c|}
\hline GND_N & Sinhalese & Tamils & Muslims & Others & Total \\
\hline \multirow{2}{*}{29} & 102123 & 117773 & 106886 & 9678 & \multirow{2}{*}{336460} \\
\cline { 2 - 5 } & $\mathbf{3 0} \%$ & $\mathbf{3 5} \%$ & $\mathbf{3 2} \%$ & $\mathbf{3} \%$ & \\
\hline
\end{tabular}

Source: Deprartment of Census and Statistics, 2012

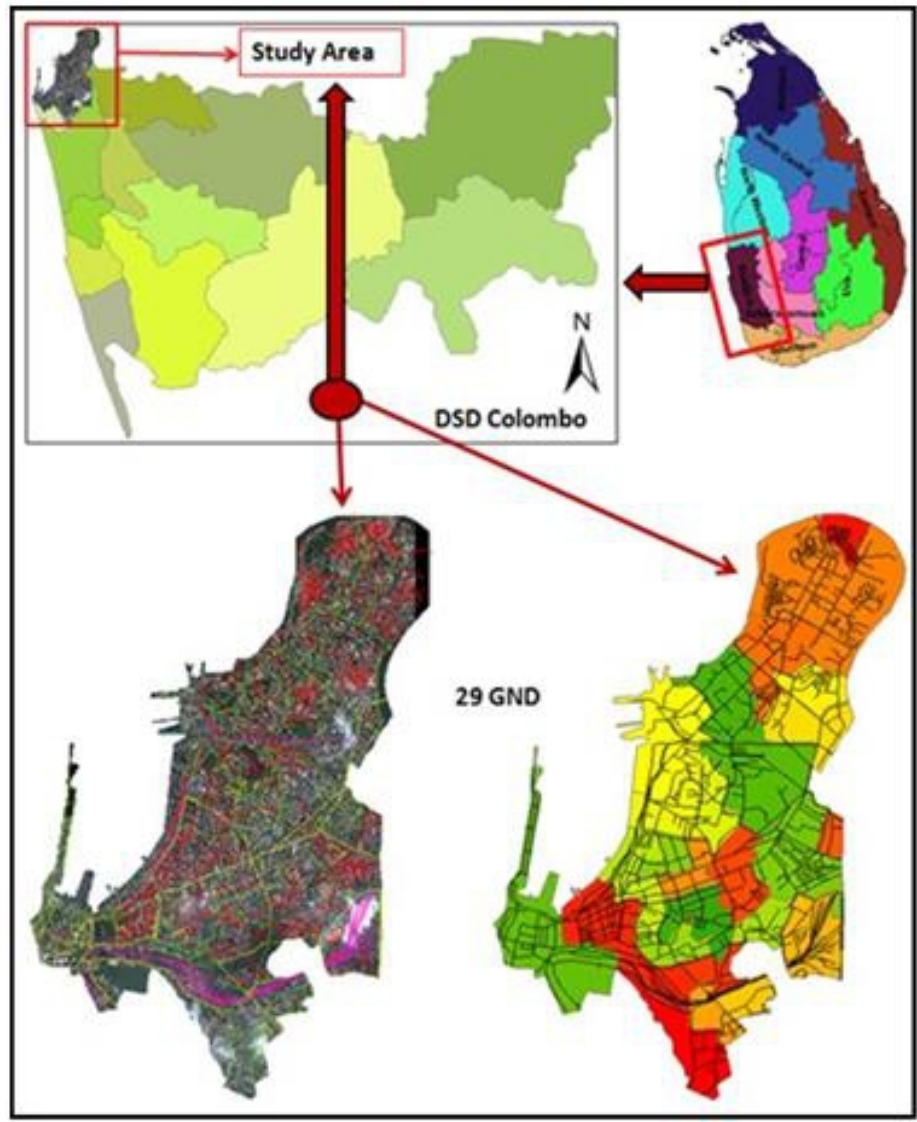

Figure 1: Study area: 29 GNDs in Colombo DSD

For the entire GIS-based road-mapping network analysis, there was a total population of 3,364,460 residents. Approximately 8,000 data, including 258 incidents, were used (164 recoveries, 43 explosions, 41 other attacks, 04 assassinations, and 07 suicide attacks). 93 vulnerable locations (figure of 7,686 suspected arrests data), 15.1702 square $\mathrm{km}$ of total land used in study area, $8.6296 \mathrm{~km}$ length of main road, $25.1799 \mathrm{~km}$ length of railroad, 84.7807 $\mathrm{km}$ length of secondary road, and $65.8757 \mathrm{~km}$ length of track road data were applied to introduce perfect road network analysis. This was carried out to respond to terrorist activities within the study area. Most of the data were 
sourced from the field survey and information was collected through personal interviews. Early-focused audience in the study area and language barriers are the major obstacles faced.

Another considerable change identified was the highly localized nature of terrorist adherents as a result of conducting covert operation. This study could be of benefit in finding countable figures of vulnerable locations within a short period. In addition, the lack of lateral cooperation within the crowd can be seen in the entire data gathering process.

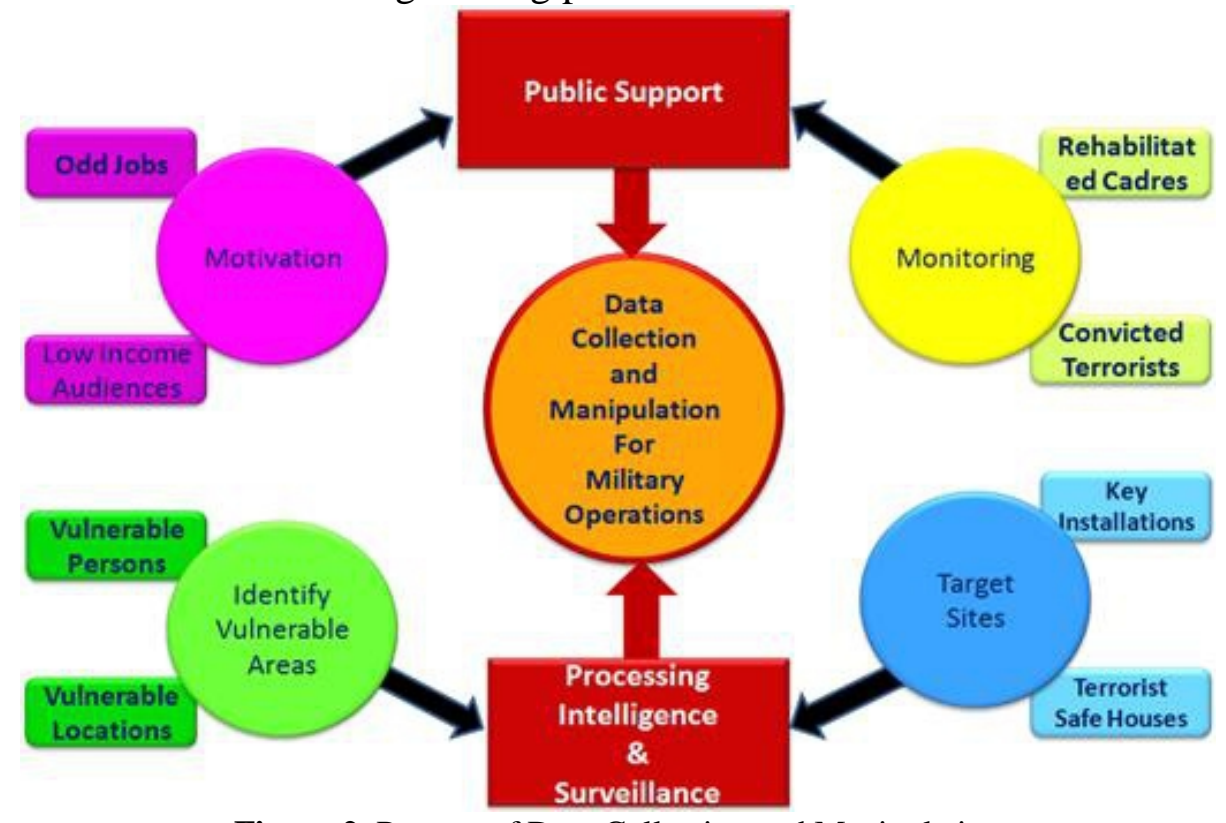

Figure 2. Process of Data Collection and Manipulation

Terrorist-related intelligence operations have been mounting on a system of domestic information gathering, the police officers, and groundlevel intelligence operatives. They could be in a better position to collect information with the support of the public. Also, certain locations can be used to receive updates on terrorist activities by using the GIS system. Additionally, the highly sensitive locations and key economic institutes were focused on treat assessment and providing security arrangement as well as venues of vulnerable public areas. They could be kept under surveillance and escape entry and exit points could be identified through GIS analysis system. As a sample of satellite data map, named GeoEye-1 (resolution $0.5 \mathrm{~m}$ and 1:10000), road layer data were used and integrated to produce good road network in study area and 1:10000 data set was the spatial referencing for WGS_1984_UTM_Zone_44N. During this process, approximately 100 - 150 roads and 350 road names were updated to produce a better road network layer set. This street network comprises main roads (normal width), secondary 
roads, railroads, and track roads. More-accurate calculations of driving distances in future analysis would require a higher level of road detail. The GeoEye maps data was used solely for reference and as a visual aid for identifying roads and building features on the maps presented for 29 GND's research area.

During the data gathering process on intelligence and surveillance, nearly 93 significant locations were identified as some vulnerable places in the study area including target sites which might affect the strategy of planning, operating, accommodating or facilitating points on operational activities of a terrorist. All known locations have been kept at close observation and coordinates have been collected (as samples) for updating system. The Euclidean (Distance to closest source) and driving to the nearest vulnerable place were calculated as well as the proximity of other such locations to any emergency service (Figure 2).

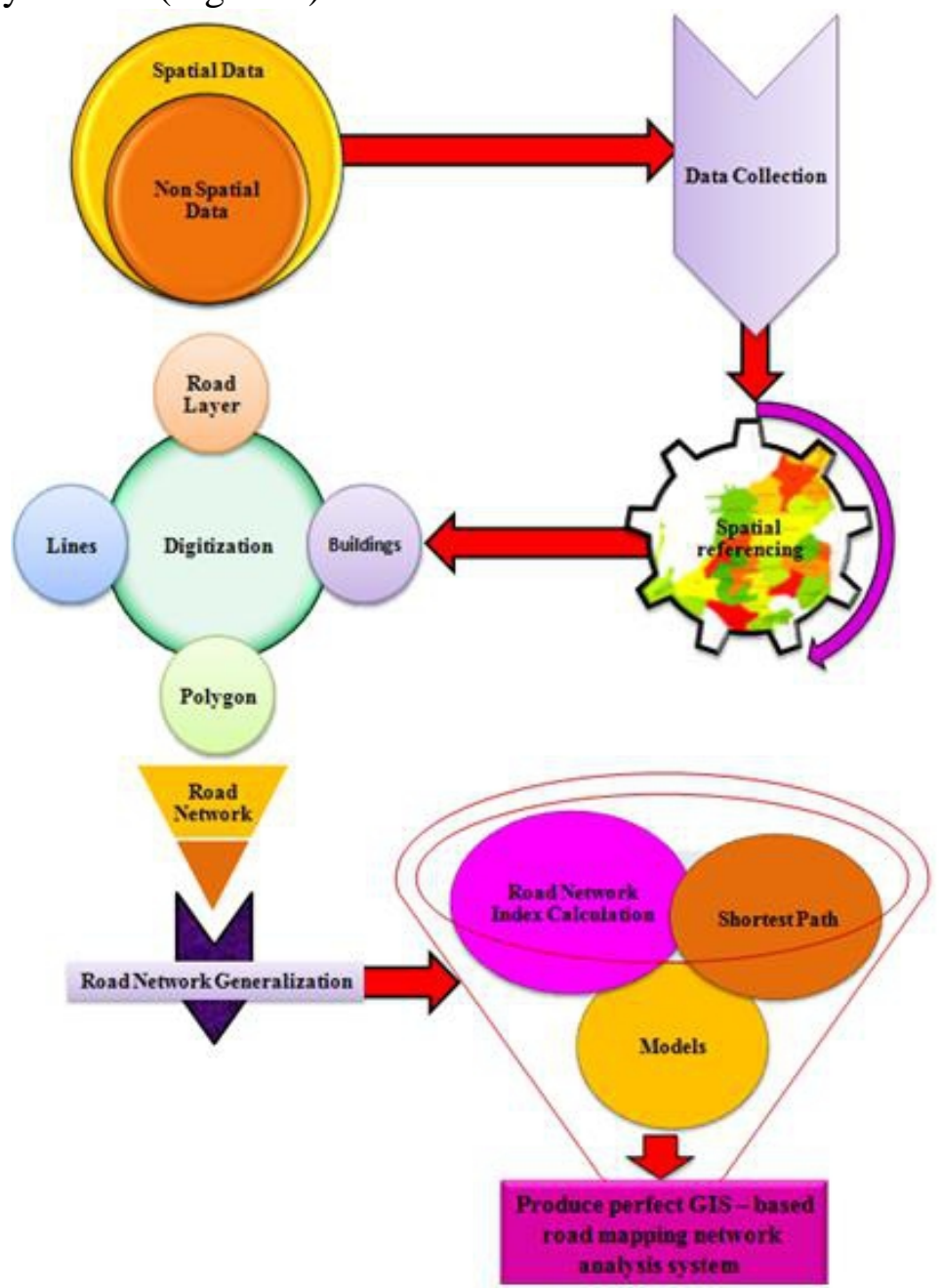

Figure 3: Data Analysis Process 
The limitation of the data in the study area posed a significant challenge to the research. There is a lack of data from large scale to microlevel information on the road network that is obtainable for an analysis process for identification and behavior pattern data, which cannot be qualitative data. The old logging roads or other unpaved paths are not listed in data sources even though they may be visible in the satellite images. The researcher has to do additional modifications of some roads and lands that would be chosen for further analysis. The creation of new road names is in line with ground sources, Google map, satellite imagery, and manually checking a hard copy with a list of nearly 1,000 secondary and minor roads into the research area. Some targeted audiences were interviewed. However, poor handling of the communication gap, language barriers, privacy, and confidentiality were limitations in the collection and submission of data on successful outcomes from various ethnic groups in the study area. This is because some persons were not ready to reveal their pattern of lifestyle. The research was also liable to lack of public awareness including some misinterpretation.

The data analysis technique is the most important area of methodology that may completely describe the GIS environment analysis and spatial database creation for related study areas as the development of road-mapping network analysis which responds to terrorist activities. ArcGIS 10.1 was used for the mapping and analysis. Also, secondary data were created in the excel files in the form of text that were converted and imported into the shape files through GIS application (Figure 3). Police records, supplementary and attribute data, textbooks, journals, ground operatives involving personal interviews, and fieldwork interactive use of Global Positioning System (GPS) provided the coordinates and respective government with authorized data to conduct spatial analysis, geo-referencing, projection, symbolization, and other processes.

\section{Results and Discussion}

According to the road network analysis, the selected area is an aggregated 1,281 routes that are used for major thoroughfares. They have also been used to produce a safe and secure road network system to stop the continuation of terrorist activities. The implemented network showed the path from security installations to the vulnerable locations. The network contained link cards identified by start and endpoints of both nodes. Each link card is a record that represents the different characteristics of a street segment. Finding the shortest path to any particularly vulnerable location from security installation is very important. This provides a rapid and economical tool in preventing and responding to any terrorist attacks.

According to Figure 4, 97 vulnerable locations and associated routes are identified by the associates of the intelligence field's ground operatives. 
The analyzed roads are spreads from Kotahena East to Colombo Fort in 12 GNDs. Minimum distance from security installation to a vulnerable location is $0.8 \mathrm{~km}$ while the maximum records is 2.4 . Therefore, average responding time from any adversary action varies from 3 to 5 Minutes. With reference to previous terrorist attacks which happened in this area, within this time response, forces can effectively reach there and control the terrorists on site.

The study area shows various categories of unsafe locations which have to be monitored regularly. Implementing temporary or permanent roadblocks to either capture suspected terrorist or block their movement is an immediate response. The analysis is used to identify the suitable locations to implement them and narrow the locations down into a minimum distance from the vulnerable location to a terrorist attack. Junctions that are ranged from 400 to $500 \mathrm{~m}$ distance from all vulnerable locations in the study area were identified as suitable road blocking points and are shown in Figure 5. By using this map, the best and closest junction within a short period can be identified. Consequently, the appropriate junction which is relatively accessible as compared to other junctions can be determined too. This would be very useful to the responders of terrorist attacks in Kotahena and Kochchikade areas of Colombo to implement road barriers that are closest, most accessible, and most effective within minimum time. Based on the parameters such as population density and the complexity of road network, buffers were created accordingly as the first radius with $10 \mathrm{~m}$, second with $20 \mathrm{~m}$, and third with 50 $\mathrm{m}$ from the selected roads in all the 29 GNDs. Figure 6 shows the buffered area as $10 \mathrm{~m}, 20 \mathrm{~m}$, and $50 \mathrm{~m}$ which focuses on 97 vulnerable locations, 30 security installations, and 90 incidents. Thus, this would likely provide more information pertinent to the investigation than areas outside the buffer.

6 out of 29 GNDs were identified as potential areas for security installations. Sammanthranapura, Mattakkuliya, Modara, Madmpitiya, Aluthmawatha, and Lunupokuna were the GNDs to be considered for further analysis. About 25 vulnerable locations, 2 security installations, and 3 incidents within the buffer area are evident. It depicts the unbalanced security installation system and a safe area for terrorist sympathizers. Twenty-seven important locations including the Presidential House may have made comparison with two key fields about 90 incidents and 30 security installations to reveal the validity of the buffer analysis. 


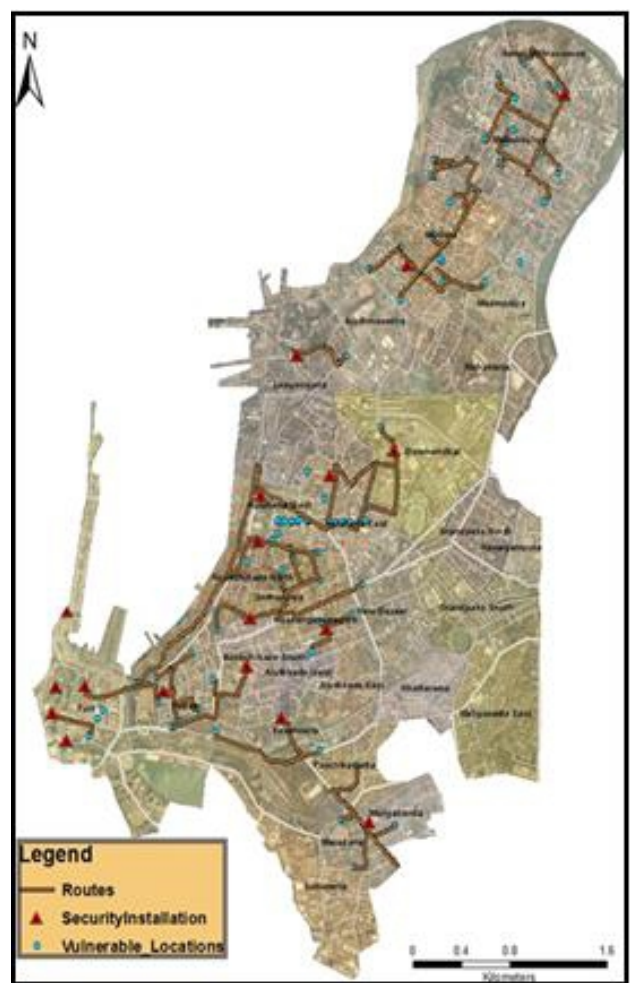

Figure 4. Shortest paths from security installations to vulnerable locations

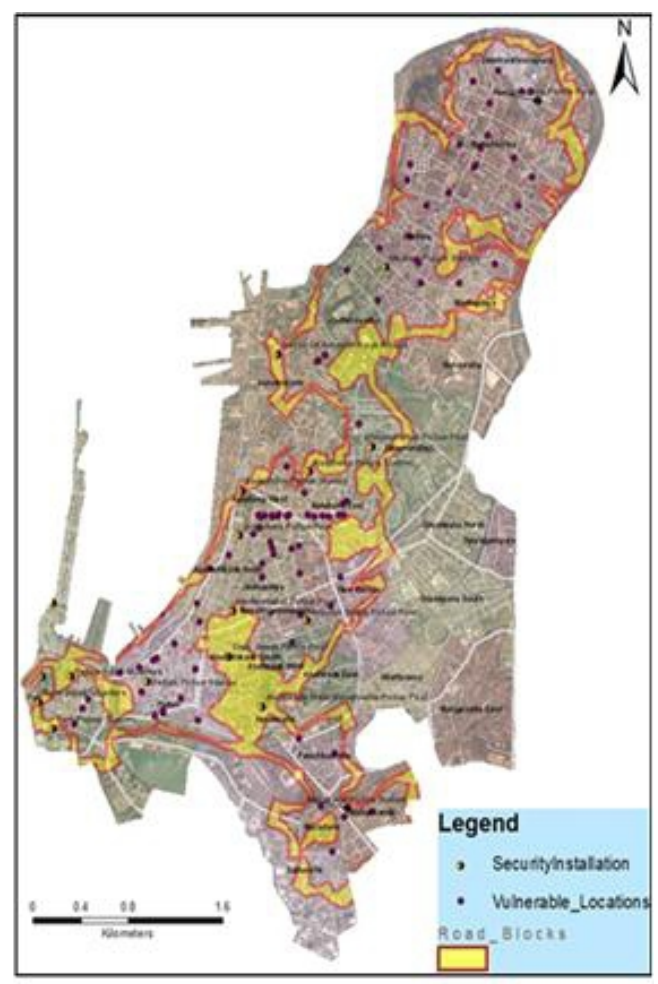

Figure 5. Most Suitable Locations for Implement Road Barriers within $400 \mathrm{~m}-500$ m Distance

Buffer analysis also produced multiple areas around 90 incidents. The buffer analysis highlights the important locations and security installations that should provide special considerations. Fort area is a most strategically significant area and 15 incidents were focused on buffer analysis. Furthermore, each location was buffered using $10 \mathrm{~m}, 20 \mathrm{~m}$, and $50 \mathrm{~m}$ and is shown in Figure 6. The standard distance is commonly displayed as a circle, on the mean center. With this zone, 5 security installations and 10 important locations have been buffered to identify the pattern of incidents and vulnerable areas so as to implement new security systems and examine threat around the 10 important locations.

Based on two main fields, the time-wise calculation at the service areas from security installations to vulnerable locations and distance-wise calculation at the service areas from incident to security installations and important locations, network service area analysis was employed encompassing all accessible streets. Service areas created by the network analysis helps to evaluate accessibility and threat assessments based on locations of security installations to vulnerable locations and incident to security installations and important locations. Both analysis of service area 
calculations could be lined up with time calculation from 1 to 5 minutes. This is between security installations to vulnerable locations and distance calculation from 200 to 400 meters within an incident to security installations and important locations.

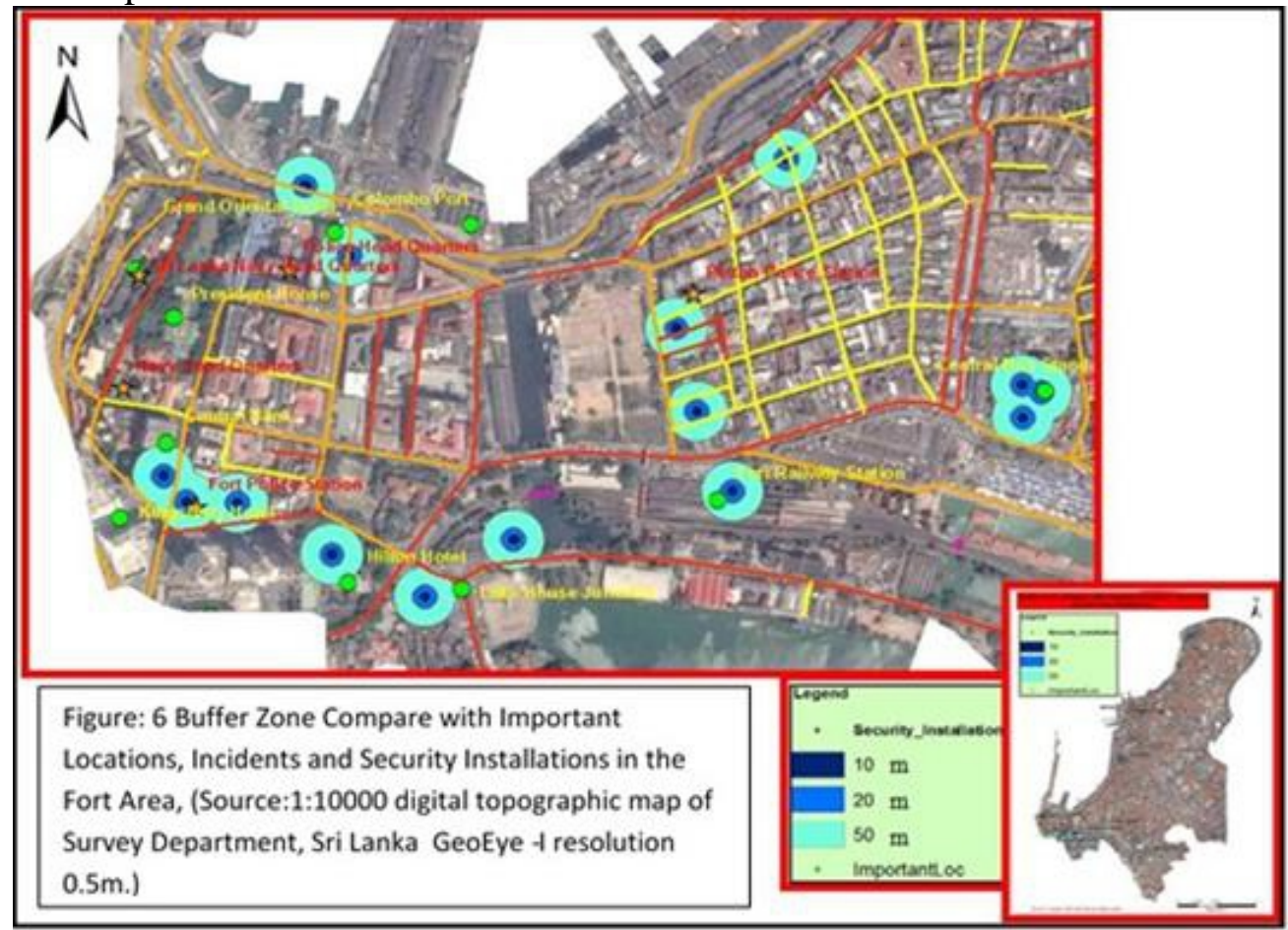

Eight police stations namely Bloumendhal, Foreshore, Jumphata Street, Wolfendahal, Armour Street, Dam Street, Pattah, and Keselwatta are analyzed with time calculation from 1 to 5 minutes. Time polygons clearly show each vulnerable point where the locations have to be rushed to respond to any terrorist activities. Using road network analysis connecting with incidents to security installations and important locations can be a platform for illustrating detail-oriented discussions about threat assessment. This service area analysis examines distance calculation within incidents to important locations. It may be developed as an effective tactic, rapid deployment, focused assessment, and a follow-up proper threat assessment. The calculated network service areas show $200 \mathrm{~m}, 300 \mathrm{~m}$, and $400 \mathrm{~m}$ polygon classes at the area and results are shown in Figure 7. Fort and its suburb area can be considered as a more significant zone. Also, it consists of 10 important locations including the President's House and Central Bank, 08 security installations, and 28 incidents. 


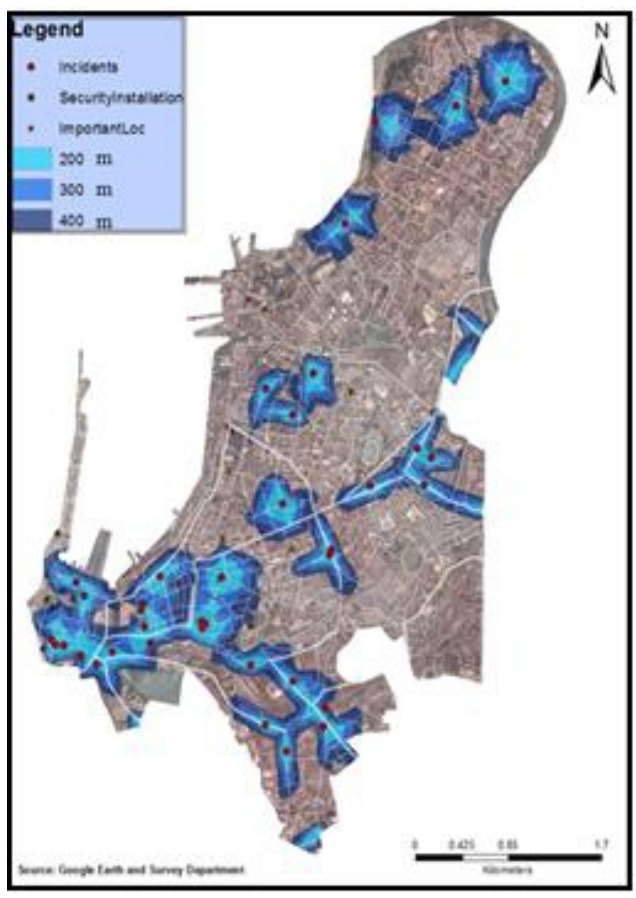

Figure 7. Service Areas from Incident to Security Installations and Important Locations

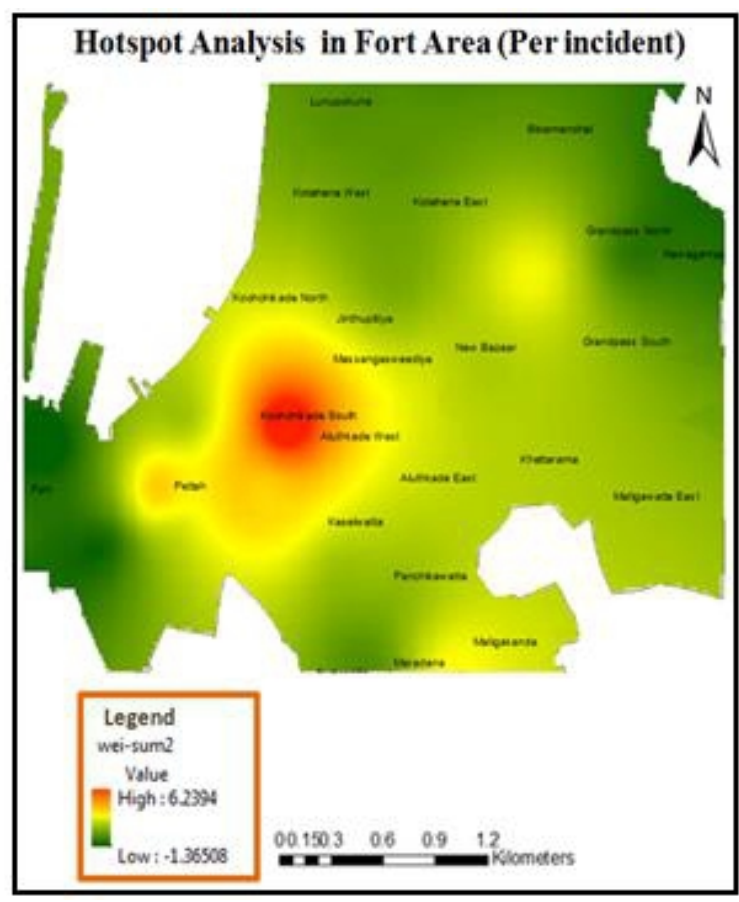

Figure 8. Hotspot Analysis on Incident Intensity

Vulnerability to terrorist attacks can be predicted through hotspot analysis integrating data on explosions, attacks, and suicide attacks. Vulnerable locations that were on or near the hotspots have severe potential to be attacked by terrorist. For example, terrorist attacks were always launched at the sites where many vulnerable locations are situated in or around the attack site. This type of spatial hotspot is characterized by any significant location. There are few hotspots which are clustered around Fort, Pettah, and its suburb. This does not negate the possibility of terrorist attacks at other locations within the hotspot. However, there is clear evidence of terrorist attacks surrounding a particular feature (Figure 8). Hence, the response teams can pay their full attention to these clustered hotspots and take preventive actions against terrorist attacks in future. The use of hotspot in this model also produced multiple areas of concerted activity. The geography of the terrorist attacks show where multiple victims share activity space and simplify a large amount of data into a visual display. Then this model copies the inputs into the output file geodatabase, prepares data to be fed into the sub-models, and calls each sub-model in turn.

Most of the major incidents (attacks, suicide attacks and explosions) occurred in the Fort area. The study illustrated the attacks that took place in the study area. These can be used in future response planning and also in 
organizing drills. The study identifies the Fort area as a high-risk location and many previous attacks also took place in that area. Therefore, more customized tailor-made solution is needed for that area. North part of the study area can be seen with only two isolated security installations with long-distance. There is therefore a need to identify suitable locations for new security installations. This study highlights the points which need to be addressed and upgraded. It also stresses out the need of the North part of the study area to be highly concentrated and for more intelligence operatives to be sent to monitor their activities. Due to previous incidents, vulnerable locations and security installations are highlighted as several escaping roots for terrorist before responding to their activities. Similarly, the study highlights the number of escaping roots for terrorist before responding to their activities. These are the loopholes of the security arrangement in the study area which need to be amended as soon as possible.

Between $10 \mathrm{~m}$ to $50 \mathrm{~m}$ areas from the roads (buffer zone) shows the vulnerability and necessity to secure such areas. The buffer analysis shows the potential risks which are not tangible to many security planning tools. As a result, in many planning, some of the vulnerable locations were underestimated against the terrorist threat. These also address and provide true risk estimation. More so, buffer analysis can be used for traffic arrangements in the area, i.e., demarcation of one-way roads, pedestrians only, no parking, etc.

Finding shortest paths from security installations to vulnerable locations for responding to any emergency is the major task of this analysis. Vulnerable locations are the important places of any area that has the potential threat of terrorist attack. The terrorist attack management can be divided into two major parts: pre-attack response and post-attack response. The material that developed during this paper covers the most vulnerable locations in the commercial capital of Sri Lanka. These materials can be directly used in preplanning, training sessions, as well as in drills to make response team ready for terrorist attacks for the selected locations. Also, these can be used as tools to reduce response time after any incidence occurred and also to increase the effectiveness of the response. The pattern of security installations is not perfectly installed to respond to terrorist activities. Although there are different types of security installations in the study area, many of them are not installed as a part of the master plan against terrorist attacks. The tools developed in this study play an important role in deciding the strategic importance of any security installation in the area. 


\section{Conclusion}

The research highlights the potential of GIS to easily incorporate with respective security installations data, overlaying with important locations and incidents, and combine with the vulnerable locations to support a broad spectrum of military and intelligence operations from the strategic level to the tactical level in any areas. The findings of this study effectively reflect the use and need of proper security installations against terrorist event management. This is because some of the existing vulnerable locations are far away from the security installations. Most of the vulnerable locations have established as clusters and can be reorganized at any emergency time. The analysis clearly shows the spatial distribution of the response forces in the study area. As a result of this aggregation in an event, many response teams get together to launch a monotonous reaction. Security response teams may have more specific, localized response plans in most significant areas which have a small spatial distribution. By viewing spatial distribution of vulnerable locations and response location, a response network can be developed by sharing and pooling the strengths and weaknesses of different response teams and vulnerable locations. Such a network will be effective against terrorisms than individual responses.

The intelligence agencies should be closely observed and checkpoints should be installed at the most suitable locations to implement road barriers within $400 \mathrm{~m}-500 \mathrm{~m}$ distance with a proper plan. Prior to response, the troops have to be offered geospatial analysis data as an option to understand validity of information and actual estimation of threat. Also, facilities to collect ground information for intelligence analytical process should be provided which would save time. Human and material resources should be put in place to bring military actions towards responding to terrorist activities. Additionally, the troops have to be briefed about the locations, geospatial patterns, the visualization of attributes, and activity patterns which intercept with terrorists without wasting valuable time and resources. Using these developed tools, the targeted location can be reached faster and effectively.

\section{References:}

1. Alexander, J. S. (2012). The Role of GIS in Asset Management: Integration at the Otay Water Districts. [Online] Available from: http://digitallibrary.usc.edu/cdm/ref/ collection/p15799coll3/id/96520.

2. Bahgat, K. \& Medina, R.M. (2014). An Overview of Geographical Perspectives and Approaches in Terrorism Research, Perspectives on Terrorism, Volume7, Issue 1. 
3. Chandraprema, C.A. (2013). Gota's War: The Crushing of Tamil Tiger Terrorism in Sri Lanka, Vijitha Yapa Publications, Colombo.

4. Fair, C. C. (2004). Urban Battle Fields of South Asia - Lessons Learned from Sri Lanka, India, and Pakistan [Online] Available from: http://www.rand.org/pubs/monographs/ MG210.html [Accessed: 27th January 2018]

5. Jones, S.G. (2017). Rebuilding the Base: How Al-Qaida Could Resurge, Testimony presented before the House Homeland Security Committee, Subcommittee on Counterterrorism and Intelligence on July 13, 2017. Available at: https://www.rand.org/pubs/testimonies/CT479.html.

6. Richardson, D. (2002). Building a Research Agenda on the Geographical Dimensions of Terrorism: An on-Going Process, Transactions in GIS, Vol.6:3. 225-29.

7. Yonah, A. (1976). International Terrorism: National, Regional and Global Perspectives. New York: Prager. 